\title{
The State of REM: Perspectives of the Outgoing Editor-in-Chief
}

The last four years have seen significant changes in our scientific journal. Originally named the Journal of Range Management, the journal has evolved into Rangeland Ecology and Management to reflect the diversity and breadth of manuscripts published. I recently switched positions and decided that the journal would benefit by having someone else take the responsibilities of Editor-in-Chief. As I end my fouryear appointment, I would like to take this opportunity to describe several of the changes that have occurred, including the transition to electronic submission and publication, and the increased breadth of the Associate Editor Board.

Electronic manuscript submission and review through Allen Track were initiated in August 2004 in partnership with Allen Press. This system enabled us to handle all manuscripts electronically and to decrease the turnaround time on both review and publication. All author correspondence was directed through the Editor-in-Chief to enable more accurate manuscript tracking. Turnaround times between manuscript submission and author notification of the initial review decision has been a median time of 94 days.

The electronic submission process enables tracking of the manuscripts during the review process. Manuscripts are received by the Editor-in-Chief the same day they are submitted and are assigned to an Associate Editor. The Associate Editor solicits reviews by sending a message to potential reviewers asking if they would agree to review the manuscript. The message provides links to either accept or decline the assignment, but this can delay the review if potential reviewers fail to respond. It would greatly decrease turnaround times if we could increase the pool of qualified reviewers, and if potential reviewers would respond to the request to review. After the last review is received, the Associate Editor reviews the manuscript and makes a recommendation, typically within 10 days. After a final decision to accept the manuscript has been made, it generally takes less than 60 days for the manuscript to appear in print.

Manuscript submissions have increased subsequent to the name change of the journal and adoption of electronic submission. For the 10 years prior to initiating electronic submission, the Journal of Range Management received 145 manuscripts per year. After an initial peak of 240 manuscripts in 2005, we now average about 185 submissions per year, the majority of which are research articles $(85 \%)$. Over the last four years, we have also received 11 synthesis papers, 31 technical notes, 38 research notes, and nine forum submissions. The final acceptance rate for research articles averages $37 \%$, rejection rates average $35 \%$, and the remaining manuscripts are either returned for revision or withdrawn after review. Acceptance rates for the other categories of manuscripts are slightly higher $(45 \%)$ and rejection rates are slightly lower $(30 \%)$.

Another benefit of electronic submission is the increase in submissions from international authors. The majority of manuscripts still originate within the United States $(66 \%)$, but we receive submissions from 23 other countries during a typical year. The most highly represented countries include China (8\%), Canada (5\%), Argentina (3\%), and Spain (2\%). Rangelands and rangeland issues are obviously a global concern, and we encourage submissions from around the world.

The Associate Editor Board has also changed to reflect the more international scope of the journal. Our expanded editorial board now represents a broader range of expertise and geographic locations. There are three Associate Editors from Australia, and one each from Canada, Israel, and Argentina, representing one-third of the entire Associate Editor Board. In addition, Miguel Flores from Mexico has served as Associate Editor for Spanish abstracts and deserves a special thank you for translating the abstracts to Spanish for the last 10 years. The current expertise on the Board covers animal nutrition and behavior, plant ecology, soils, remote sensing, wildlife ecology, grazing systems, economics, and social policy. Occasionally a guest Associate Editor will handle manuscripts that require expertise not on our current Board. The Associate Editor Board is responsible for evaluating scientific content including the presentation and analysis of data, and ensuring that manuscripts represent new knowledge in our profession. Without the volunteers of the Board, the journal would not function and I thank them for their dedication and perseverance.

The journal has undergone many changes over the last four years, and it has been a challenging and rewarding experience to be Editor. I believe that David Briske, the new Editor-inChief, will foster the development of the journal and increase the stature and scope of the journal. In conclusion, the journal represents the scientific component of the Society for Range Management, and continued efforts to improve the journal will reflect well on the Society for Range Management and the disciplines associated with rangeland ecology and management.

M. Keith Owens, Oklahoma State University, Stillwater, OK, USA 